\title{
Mantle lithosphere transition from the East European Craton to the Variscan Bohemian Massif imaged by shear-wave splitting
}

\author{
L. Vecsey, J. Plomerová, V. Babuška, and PASSEQ Working Group \\ Geophysical Institute, Academy of Sciences of the Czech Republic, Boční II/1401, 14131 Prague, Czech Republic \\ Correspondence to: L. Vecsey (vecsey@ig.cas.cz)
}

Received: 19 December 2013 - Published in Solid Earth Discuss.: 17 January 2014

Revised: 23 June 2014 - Accepted: 28 June 2014 - Published: 6 August 2014

\begin{abstract}
We analyse splitting of teleseismic shear waves recorded during the PASSEQ passive experiment (20062008) focused on the upper mantle structure across and around the Trans-European Suture Zone (TESZ). Altogether 1009 pairs of the delay times of the slow split shear waves and orientations of the polarized fast shear waves exhibit lateral variations across the array, as well as back-azimuth dependences of measurements at individual stations. Variable components of the splitting parameters can be associated with fabrics of the mantle lithosphere of tectonic units. In comparison with a distinct regionalization of the splitting parameters in the Phanerozoic part of Europe that particularly in the Bohemian Massif (BM) correlate with the largescale tectonics, variations of anisotropic parameters around the TESZ and in the East European Craton (EEC) are smooth and of a transitional character. No general and abrupt change in the splitting parameters (anisotropic structure) can be related to the Teisseyre-Tornquist Zone (TTZ), marking the edge of the Precambrian province on the surface. Instead, regional variations of anisotropic structure were found along the TESZ/TTZ. The coherence of anisotropic signals evaluated beneath the northern part of the Brunovistulian in the eastern rim of the $\mathrm{BM}$ and the pattern continuation to the NE towards the TTZ, support the idea of a common origin of the lithosphere micro-plates, most probably related to Baltica. Smooth changes in polarizations of the core-mantle boundary refracted shear waves (SKS), polarizations, or even a large number of null splits northward of the BM and further across the TESZ towards the EEC indicate less coherent fabrics and a transitional character of structural changes in the mantle beneath the surface trace of the TESZ/TTZ. The narrow and near-vertical TTZ in the crust does not seem to have a steep continuation in the mantle lithosphere. The mantle
\end{abstract}

part of the TESZ, whose crust was formed by an assemblage of suspect terranes adjoining the EEC edge from the southwest, appears in our measurements of anisotropy as a relatively broad transitional zone in between the two lithospheric segments of different ages. We suggest a southwestward continuation of the Precambrian mantle lithosphere beneath the TESZ and the adjacent Phanerozoic part of Europe, probably as far as towards the Bohemian Massif.

\section{Introduction}

The Trans-European Suture Zone (TESZ) represents a distinct tectonic feature that can be traced through northwestern to southeastern Europe at a length of $\sim 3500 \mathrm{~km}$ and manifests the contact zone between the Precambrian and Phanerozoic Europe (Fig. 1). The two parts of Europe differ not only as to their ages, but also in their structure and in several other physical parameters, which can be traced in various geophysical models of the region, e.g. in seismic velocities, anisotropy, and heat flow (e.g. Spakman, 1991; Babuška et al., 1998; Piromallo and Moreli, 2003; Majorowicz et al., 2003; Artemieva, 2009; Jones et al., 2010; Debayle and Richard, 2012). The East European Craton (EEC) appears as a large rigid domain with a thick lithosphere that is bordered in the southwest by a relatively narrow linear Teisseyre-Tornquist fault zone (TTZ). On the other hand, the region westward of the TESZ represents a Variscan assemblage of micro-plates with varying lithosphere thickness and fabrics, partly rimmed by rifts and subduction zones reflecting micro-plate collisions (e.g. Plomerová and Babuška, 2010). The central part of the long TESZ, running through the territory of Poland, is a zone of about $150-200 \mathrm{~km}$ wide. 


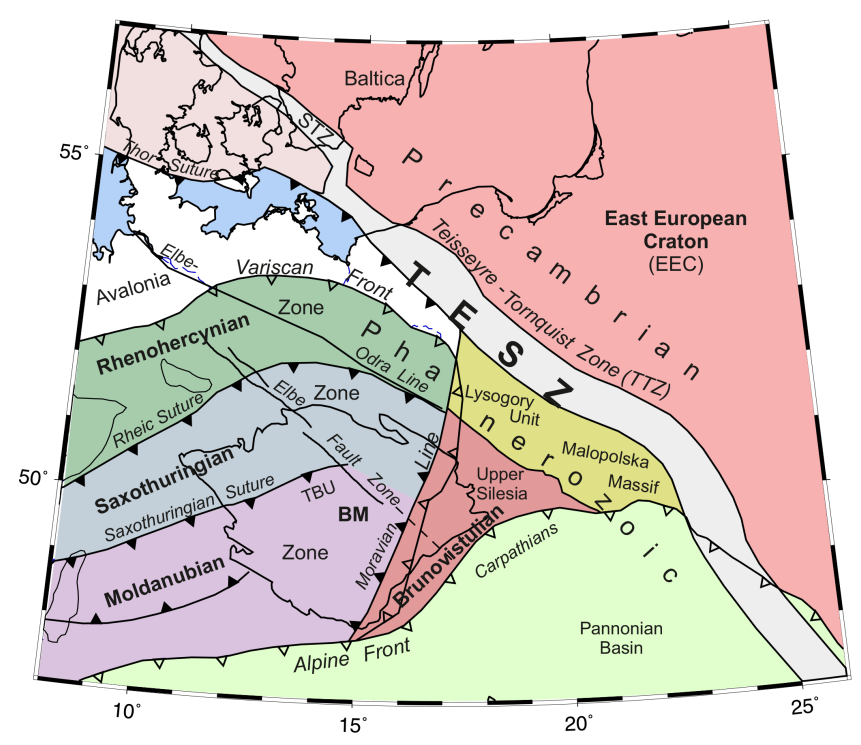

Figure 1. Simplified tectonic sketch of the Trans-European Suture Zone (TESZ) and adjacent areas according to Pharaoh (1999). STZ stands for the Sorgenfrei-Tornquist Zone, TBU for the TepláBarrandian Unit included in the Moldanubian Zone of the Bohemian Massif (BM).

The term TESZ was introduced for an assemblage of suspect terranes adjoining the EEC edge from the southwest (Berthelsen, 1992) and the TTZ thus marks the northeastern boundary of the TESZ (Dadlez et al., 2005, see Fig. 1).

Three decades of controlled-source seismic (CSS) exploration of the TESZ crust (Guterch et al., 1986, 1994; Grad et al., 1999, 2003; Janik et al., 2002, 2005; Środa et al., 2002; Wilde-Piórko et al., 1999, 2010) resulted in detailed, but often different interpretations of its structure. But in general, structure of the crystalline crust of the TESZ, covered by up to $12 \mathrm{~km}$ thick sediments, seems to be more complicated than that of the Variscan belt to the west and of the EEC, with sudden structural changes observed laterally along the suture (Dadlez et al., 2005). The authors, as well as Narkiewicz et al. (2011), interpret the complex structure of the broad TESZ as a result of detachment and accretion of lithospheric fragments of Baltica, Avalonia and various Gondwana-derived exotic terranes. To better understand processes that formed this part of Europe, we have to look deeper beneath the crust, i.e. into the lower lithosphere and the upper mantle below, and probe their velocity structure and fabrics.

The PASSEQ array of seismic stations (Fig. 2 and http: //geofon.gfz-potsdam.de/db/station.php, network code PQ) was designed to record teleseismic data during 2006-2008 for studying variations of the upper mantle velocity structure across the TESZ. The array spans across the central part of the TESZ and covers a vast band of $\sim 1000 \mathrm{~km}$ long and $\sim 600 \mathrm{~km}$ broad (Wilde-Piórko et al., 2008). Densely spaced broad-band (BB) and short-period (SP) stations are mixed in the central band of the array. Seven parallel lines of SP and of

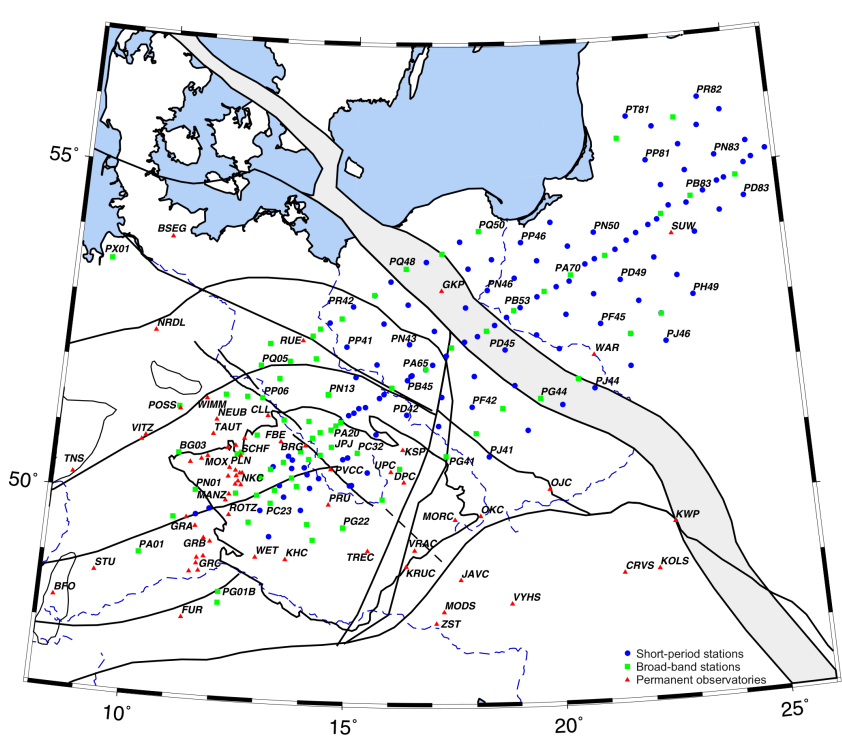

Figure 2. Seismic stations of the passive experiment PASSEQ (2006-2008) designed to study upper mantle structure of the TESZ. Labels are assigned to some of stations for easier orientation.

BB stations complement on both sides the central backbone of the array. In combination with other large-scale European passive seismic experiments, particularly with the TOR, which covered the northwestern part of the TESZ (Gregersen et al., 2002), and the SVEKALAPKO, which concentrated on upper mantle structure around the Proterozoic/Archean contact in south-central Fennoscandia (Hjelt et al., 2006), the PASSEQ array complements the international data sets needed for high-resolution studies of the European lithosphere and the upper mantle, to help in answering questions on structure and evolution of the continent.

In this paper, we present our findings on the mantle structure derived from shear-wave splitting, evaluated from teleseismic data recorded during the PASSEQ array operation. The research aims at detecting changes in anisotropy of the upper mantle beneath the TESZ and surrounding tectonic units. Mapping variations of anisotropic structure of the upper mantle helps answer questions on how the zone, approximately delimited at the surface, may continue down to the upper mantle, as well as on a possible identification of individual blocks building the lower lithosphere.

\section{Data and method}

Shear-wave splitting represents nowadays a standard method to measure seismic velocity anisotropy of the upper mantle. Various methods are applied to get splitting parameters and to model anisotropy of the continental upper mantle (e.g. Vinnik et al., 1989; Silver and Chan, 1991; Silver and Savage, 1994; Menke and Levin, 2003), each of them having both advantages and limitations (Vecsey 
et al., 2008; Wüstefeld and Bokelmann, 2007). To retrieve 3-D orientation of large-scale anisotropic structures in the upper mantle, we have applied a modified version (Vecsey et al., 2008; code SPLITshear, www.ig.cas.cz/en/ research-teaching/software-download) of a method introduced by Š́lený and Plomerová (1996). The method exploits signals on all three components of the broad-band recordings and analyses them in the ray-parameter coordinate system (LQT). To study lateral variations of the anisotropic signal in detail, for which we need densely spaced seismic stations, we included also waveforms recorded by medium-period seismographs $(T s \sim 5 \mathrm{~s})$ into the splitting analysis, because the dominant period of shear waves is in the range of 8-10 s for most of the broad-band recordings. Some stations, equipped with 2-3 s seismometers, allowed analysing shear waves as well. However, we always mark anisotropic parameters evaluated at these stations in a different way and consider them as complementary, and only if they are consistent with results of surrounding BB stations. All waveforms were filtered by the third order Butterworth band-pass filter 3-20 s. For details of the method see Vecsey et al. (2008). Here we describe only the main principles needed for understanding our figures and results.

Figure 3 shows an example of splitting of the shear wave refracted at the core-mantle boundary (SKS) recorded at temporary station PA65. In total we obtained 1009 pairs of splitting parameters from the PASSEQ recordings, including null measurements (Supplement Table S1). The fast $S$ polarizations and split delay times could be determined at 158 stations of the PASSEQ array, with 6.4 splitting pairs per station, on average. Splitting evaluations from all 15 events were feasible at 19 stations of the array. The shear-wave splitting parameters are evaluated by minimizing energy on transverse component $T$ (Vecsey et al., 2008), which is the original method of Silver and Chan (1991) which we modified into the ray-parameter LQT coordinate system. The broad elliptical particle motion (PM) calculated from the QT components changes to a linear one for the fast $(F)$ and slow $(S)$ components after the coordinate rotation and applying a time shift correcting the splitting delay. The minimum of a misfit function in the $(\delta t, \psi)$ space, where $\delta t$ is a time shift between the fast and slow split shear waves and $\psi$ is orientation of the fast shear wave in the $(Q, T)$ plane, defines the splitting parameters, with which one can measure the velocity anisotropy. Depth and steepness of the minimum along with the bootstrap diagrams are used to evaluate the reliability of the measurements. The orientation of the fast shear wave given by an angle $\psi$ in the $Q T$ plane is defined by two angles - azimuth $\varphi$ (measured from the north clockwise) and inclination angle $\theta$ measured from the vertical axis upwards. Because polarizations often differ for waves coming from opposite directions (i.e. from azimuth $\varphi$ and from $\varphi+180^{\circ}$ ), in spite of their steep incidences, we always denote the polarization azimuth by an arrow pointing from a station, or from a ray-piercing point, in the down-going direction. This way

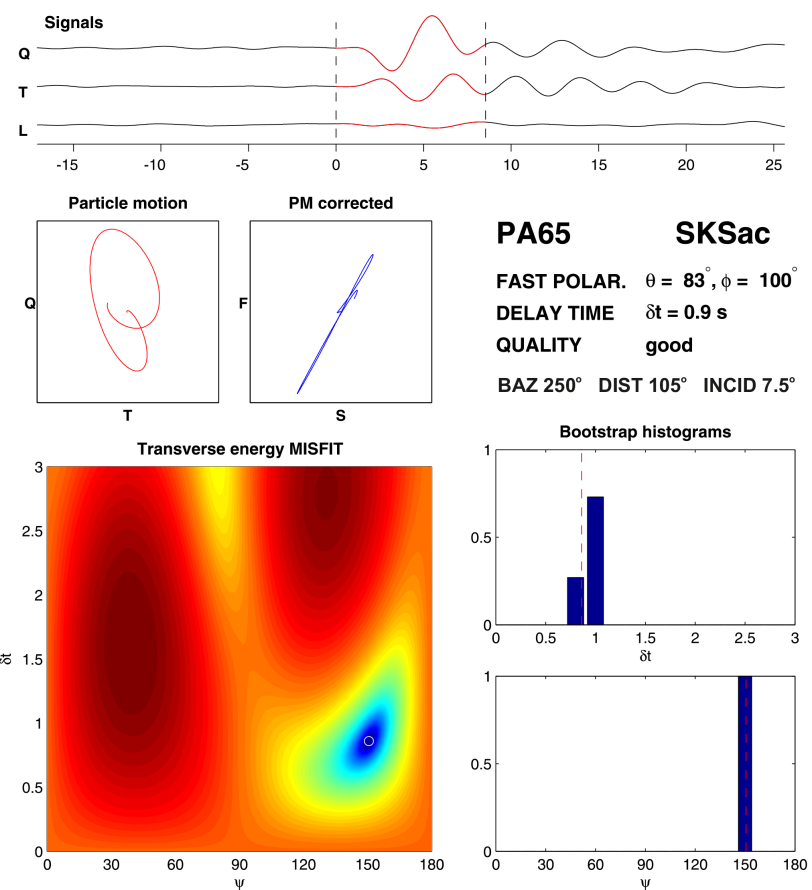

Figure 3. Example of evaluation of SKSac phase splitting at station PA65 in the central part of the PASSEQ array (see Fig. 2) for an earthquake in the Chile-Argentina border region: 2006-08$25 \_00: 44,24.34^{\circ} \mathrm{S} 67.01^{\circ} \mathrm{W}, 185 \mathrm{~km}$ deep, $5.8 \mathrm{Mw}$. Epicentral distance to the station is $105.2^{\circ}$, back-azimuth $250.0^{\circ}$ and incidence angle $7.5^{\circ}$. For more details of the method see Vecsey et al. (2008).

of presenting the results shows fast $S$ orientation systematically and allows us to detect boundaries between mantle domains with differently oriented anisotropy (Fig. 4). Such an approach allows us to depict variations of the splitting parameters in the full $0-360^{\circ}$ back-azimuth range (i.e. including different polarizations for opposite directions), though usually the parameters are plotted at modulo-90. This improves the azimuth coverage only artificially and, moreover, implements an assumption of horizontal symmetry axes. Vecsey et al. (2011) demonstrate a clear $360^{\circ}$ periodicity of synthetic splitting parameters calculated for a model with a tilted axis. However, noise in the data causes a tendency to $90^{\circ}$ periodicity, which can be misinterpreted as a double-layer model.

While processing the data of the PASSEQ array, we faced several difficulties. Careful processing of the data mostly made it possible to reveal mistakes caused, e.g. by an interchange of the $N, E, Z$ components, or by polarity flipping, though it was not always straightforward, particularly when both errors occurred simultaneously. Nevertheless, incorrect seismometer orientation to the north proved to be the most difficult obstacle. When a suspicion of a misorientation appeared, we superimposed all particle motion PM plots at a station (Fig. 5) and searched for a systematic deviation of the PM. Poor linearity of the corrected particle motion patterns is another indication of sensor misalignment (Liu and 
Two anisotropic blocks of hexagonal symmetry with divergently dipping 'fast' axes

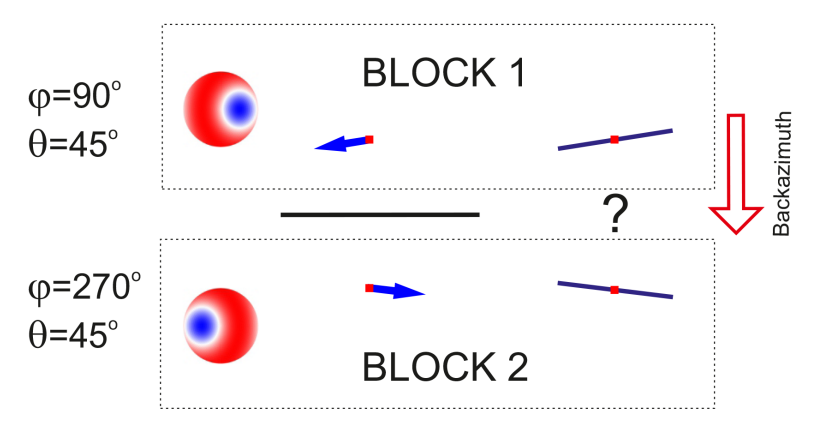

Figure 4. Fast $S$ polarizations evaluated for synthetics propagating through two blocks with divergently inclined fast symmetry axes. The "arrow style" of presentation shows the domain boundary while the standard approach (azimuthal) does not.

Gao, 2013). We estimate that with the use of the PM stacking technique only misorientations larger than $\sim 10^{\circ}$ can be identified, because individual PMs can vary due to structure and noise and can form at some stations two different groups in dependence on back azimuths. Figure 5 shows PMs that clearly identified misoriented seismometers at two stations - PC23 (temporary) and GKP (permanent) - in contrast with the PMs at JAVC with seismometer well oriented to the north. Our estimates of the deviations attain 28 and $41^{\circ}$ at the PC23 and GKP stations, respectively (Table 1). We can thus conclude that a distance between stations should be small relative to expected variations in structure, in order to eliminate potential technical errors, which could otherwise be misinterpreted as effects of mantle structure.

We have tested a potential danger of seismometer misorientation by analysing signals of different quality on welloriented components and then on the horizontal components rotated only by $5^{\circ}$ off correct direction, which simulated a seismometer misalignment. Changes in split delay times of a waveform classified as "good" lie within the error interval, but azimuths of the fast polarization differ by $15^{\circ}$, if the "minimum $T$ energy method" is used (Table 2). The "eigenvalue method" returns well the "new" polarization azimuth. On the other hand, in the case of "fair" signals the difference in polarization azimuths, evaluated by the "minimum $T$ energy method" from original recordings and from those rotated by $5^{\circ}$, attains $67^{\circ}$. The "eigenvalue method" returns the fast polarization azimuth that differs by $5^{\circ}$ from the original recordings, but it doubles the split delay time regardless of seismometer orientation (Table 2). Vecsey et al. (2008) showed that the "minimum $T$ energy method" is more robust than the "eigenvalue method" in the case of noise in a signal. However, as we show here, the "minimum $T$ energy method" appears to be more sensitive to potential errors in seismometer orientation. High accuracy in the northward orientation of seismometers can and should be technically ensured, e.g.

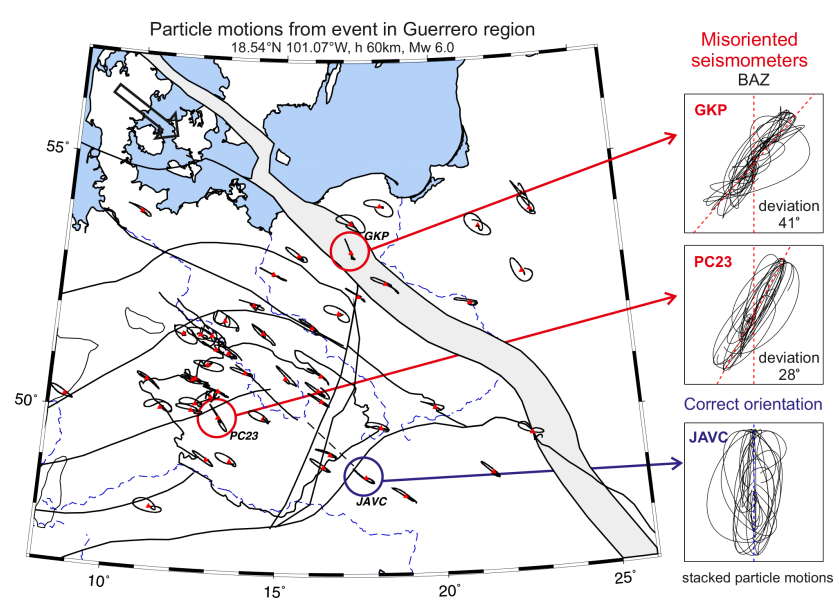

Figure 5. Horizontal shear-wave particle motion (PM) across the PASSEQ array for an event from the NW (left), located in Guerrero region, documenting incorrect northward orientation of seismometers at stations GKP and PC23. PMs rotated to the back azimuths and stacked for all events evaluated at stations PC23 and GKP with misoriented seismometers, and correctly aligned seismometer at JAVC (right). Only sufficiently large errors $\left(\sim>10^{\circ}\right)$ in seismometer misorientation can be revealed by this method. Smaller deviations of the PM can be caused by a weak anisotropy in the upper mantle.

with the use of a gyrocompass during station installations, but we can hardly avoid noise completely. Stacking of individual splitting measurements from waves closely propagating through the mantle can help to reveal a distortion of splitting parameters due to noise in signals. Therefore, we consider the "minimum $T$ energy method" as the most robust for analysing SKS waves, which should exhibit linear polarizations, i.e. no energy on the $T$ component, when reaching the bottom of an anisotropic medium.

\section{Results}

Most papers presenting results of shear-wave splitting analysis search for an azimuth of the fast shear phase and a split delay time $(\delta t)$ of the slow shear phase. The azimuth of the fast shear wave is then a priori associated with the horizontal direction of the "fast" olivine axis $a$ of a model mantle peridotite. To summarize all shear-wave splitting parameters evaluated in such "standard" way, we plot average fast shear-wave polarizations (see Supplement Table S1 for individual measurements) as bars with their length proportional to the split delay time (Fig. 6a). Though this presentation shows only azimuthal anisotropy with the $\pi$-periodicity, we can identify main large upper mantle provinces with different anisotropic signal: the orientations from $\mathrm{W}-\mathrm{E}$ prevail in the Bohemian Massif (BM) in general (see Babuška et al., 2008), less coherent fast $S$ orientations occur to the northwest of the BM, while between the Moravian Line and the 
Table 1. Estimated deviations of misaligned seismometers.

\begin{tabular}{llccrr}
\hline Station & $\begin{array}{l}\text { Permanent/ } \\
\text { temporary }\end{array}$ & $\begin{array}{c}\text { Latitude } \\
\left({ }^{\circ}\right)\end{array}$ & $\begin{array}{c}\text { Longitude } \\
\left({ }^{\circ}\right)\end{array}$ & $\begin{array}{r}\text { Misorien- } \\
\text { tation }\left(^{\circ}\right)\end{array}$ & $\begin{array}{r}\text { Number } \\
\text { of PMs }\end{array}$ \\
\hline BFO & perm & 48.3301 & 8.3296 & -12 & 1 \\
BSEG & perm & 53.9353 & 10.3169 & 12 & 15 \\
FUR & perm & 48.1629 & 11.2752 & -12 & 15 \\
GKP & perm & 53.2697 & 17.2367 & 41 & 15 \\
KOLS & perm & 48.9333 & 22.2731 & -15 & 2 \\
JAC & temp & 50.3718 & 12.9132 & -49 & 14 \\
PA10 & temp & 50.4903 & 13.1355 & -10 & 15 \\
PA69 & temp & 53.2387 & 19.8420 & 24 & 11 \\
PA70 & temp & 53.4720 & 20.5229 & -10 & 10 \\
PC21 & temp & 49.6700 & 12.6780 & 10 & 13 \\
PC23 & temp & 49.9774 & 13.1686 & 28 & 14 \\
PC32 & temp & 50.7915 & 15.1957 & 13 & 13 \\
PG41 & temp & 50.7510 & 17.3330 & -22 & 11 \\
PG42 & temp & 51.0980 & 18.0640 & -22 & 14 \\
PG01 & temp & 48.4204 & 12.0779 & 56 & 1 \\
PR04 & temp & 52.4098 & 12.9744 & 26 & 3 \\
\hline
\end{tabular}

Table 2. Synthetic tests of seismometer misorientation.

\begin{tabular}{llllllr}
\hline \multirow{2}{*}{ Signal } & Splitting & \multicolumn{2}{c}{ Original } & & \multicolumn{2}{c}{$5^{\circ}$ misoriented } \\
\cline { 2 - 4 } \cline { 7 - 8 } quality & method & $\delta t(\mathrm{~s})$ & $\varphi\left({ }^{\circ}\right)$ & & $\delta t(\mathrm{~s})$ & $\varphi\left(^{\circ}\right)$ \\
\hline \multirow{2}{*}{ Good } & transverse & 0.6 & 77 & & 0.7 & 92 \\
& eigenvalue & 0.6 & 86 & & 0.6 & 81 \\
\multirow{2}{*}{ Fair } & transverse & 0.6 & 200 & & 0.8 & 133 \\
& eigenvalue & 1.2 & 208 & & 1.2 & 213 \\
\hline
\end{tabular}

Carpathians front in the east of the region, the NW-SE average polarizations are very stable and the signal is strong even in close vicinity of the TTZ. This is not the case in the region north of the Elbe-Odra Line. Further to the east, across the TTZ, the anisotropic signals are also less coherent. Beneath the EEC the anisotropic signal is weaker in comparison with that southwest of the TTZ and particularly in the Bohemian Massif.

The location of the PASSEQ array was unfavourable for recording SKS phases, because they do not cover a complete back-azimuth range (see inset of Fig. 6a). Earthquakes, which occurred during the recording period of the array at epicentral distance larger than $85^{\circ}$ and with a sufficient shearwave signal/noise ratio, concentrate into two back-azimuth fans: $30-70^{\circ}$ and $240-300^{\circ}$. By separating polarizations of SKS waves arriving from western and northeastern azimuths, one can get a better insight into geographical variations of the splitting parameters and directional variations at a site (Fig. 6b). We also show individual polarizations as arrows pointing from ray-piercing points at a depth of $80 \mathrm{~km}$ with their lengths proportional to the split delay times (Fig. 7).
Null-split measurements are also included (see Supplement Table S1).

The splitting parameters evaluated from the PASSEQ recordings of SKS phases depend on back azimuth and exhibit significant lateral variations within the array (Figs. 811). Because two directions of SKS shear-wave propagation dominate, we divide the anisotropic signals into two groups comprising nearby events, whose back azimuths are very close and lie towards the NE and the NW. Combining results for nearby events allows us to eliminate incorrectly determined parameters (see also Liu and Gao, 2013) and to recognize reliably geographical changes of mantle structure.

Several provinces, exhibiting their own characteristics of the shear-wave PM and apparent splitting parameters, can be delimited around the TESZ. Broad elliptical polarizations within the BM with mostly NW-W oriented fast S polarizations, progressively turn to narrow PMs and null splits at stations north of the BM for waves from the NE (Figs. 8 and 9). In comparison with the lateral extent of the BM, there are only small regions indicating a consistent anisotropic signal in the upper mantle to the north of the massif along the PASSEQ array. Clear and coherent anisotropic signals come from shear waveforms at stations in a relatively small region around the $14^{\circ} \mathrm{E}$ longitude and between 51.5 to $52^{\circ} \mathrm{N}$ latitude, in the central part of the array crossing the TESZ and at some stations located in the EEC, east of the TTZ (Fig. 8, see also Fig. 1). SKS phases arriving at stations located along the northwestern rim of the array do not split at all, only with the exception of the small region mentioned above.

Three bands of marked PMs evaluated from recordings of the BB stations (Fig. 9) emphasize variations of the anisotropic signal across and along the TESZ for waves arriving from the NE. The width of the bands relates to the 

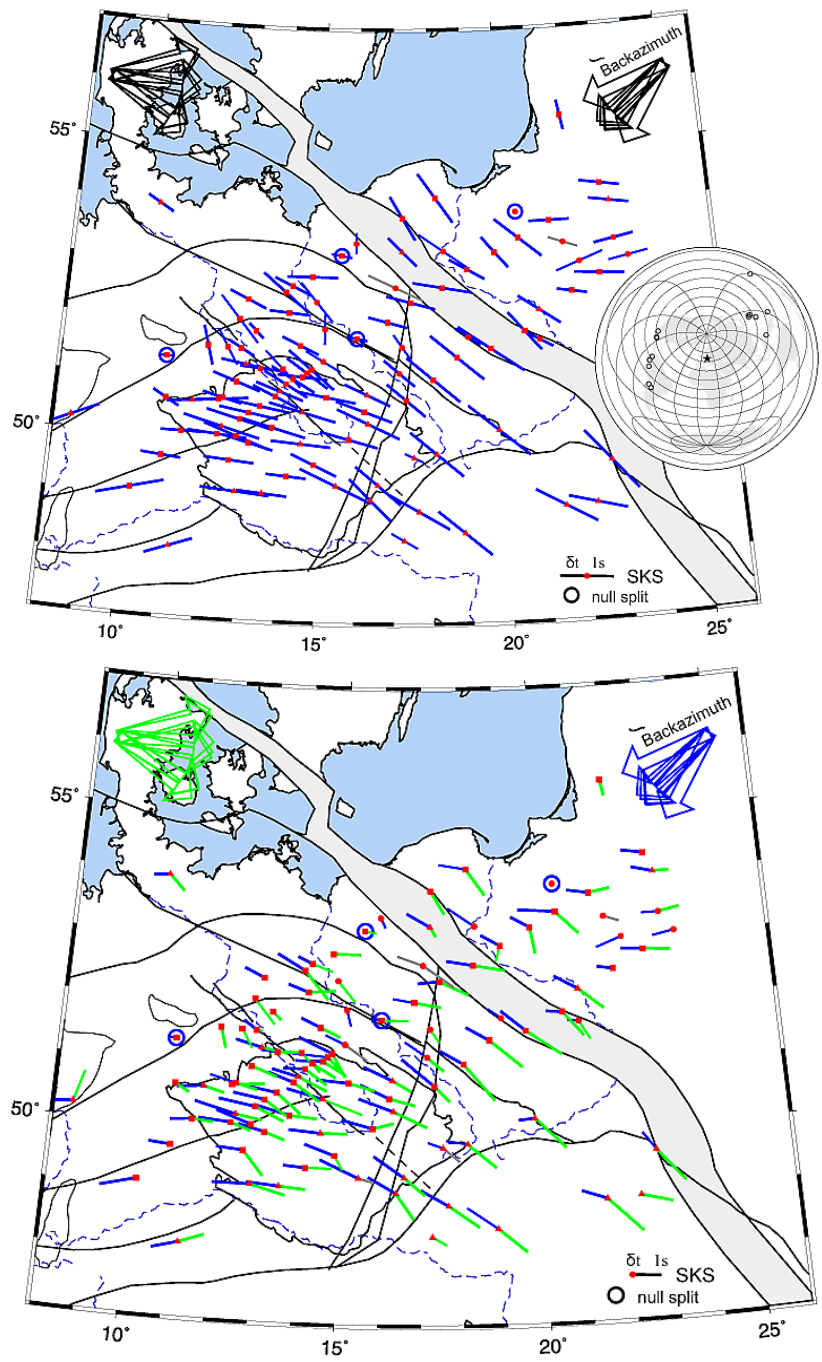

Figure 6. Shear-wave splitting presented in a standard way, i.e. the fast shear-wave polarization azimuths (Supplement Table S1) as bars with length proportional to the split delay time: (a) averages calculated from all measurements regardless of wave back azimuth and (b) averages calculated separately for waves arriving from the west and from the northeast. Inset shows epicentre distribution of 15 events used in this study relative to the PASSEQ array (star).

width of the PMs. Further off the BM to the NE along lines I and II of the array, the PMs again broaden indicating significant amount of anisotropy in the upper mantle, while along line III the narrow PMs, indicating minor anisotropy or near-symmetry axis propagations, prevail. Besides changes of the PM traced along the lines I-III, i.e. across the TESZ, significant changes in shear-wave polarizations along the TESZ/TTZ are evident as well. The anisotropic signal below the TESZ detected at stations of the central line I almost disappears at stations on lines II and III. Unfortunately, the majority of signals at stations located just at the TESZ are contaminated by noise. If well resolved, directions of the fast

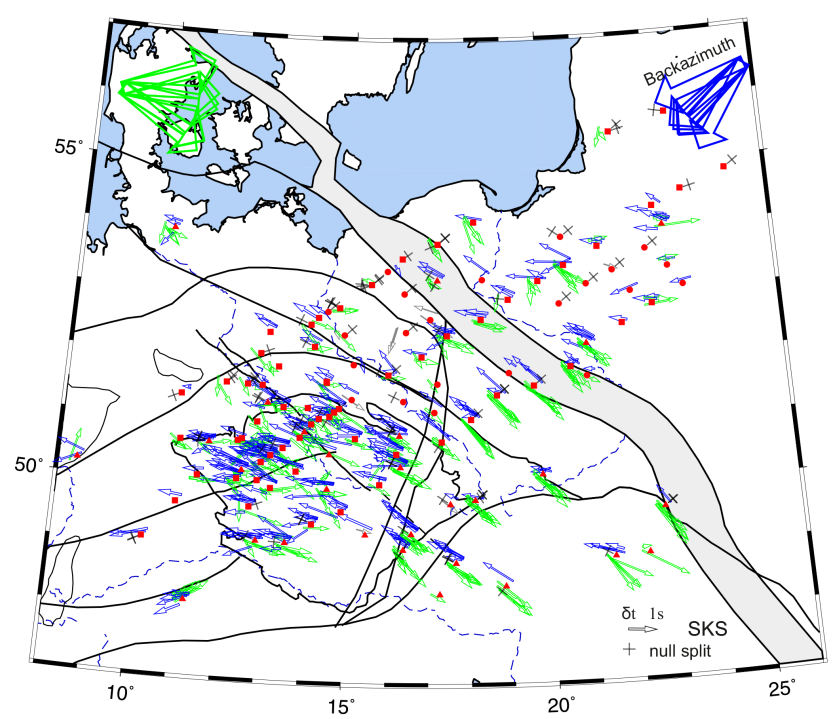

Figure 7. Fast shear-wave polarizations $(\psi, \delta t)$ evaluated in the LQT coordinate system presented at ray-piercing points at depth of $80 \mathrm{~km}$. The arrows mark azimuths $\varphi$ of the polarized fast split shear waves and point in down-dip directions. See also Fig. 3 and related text.

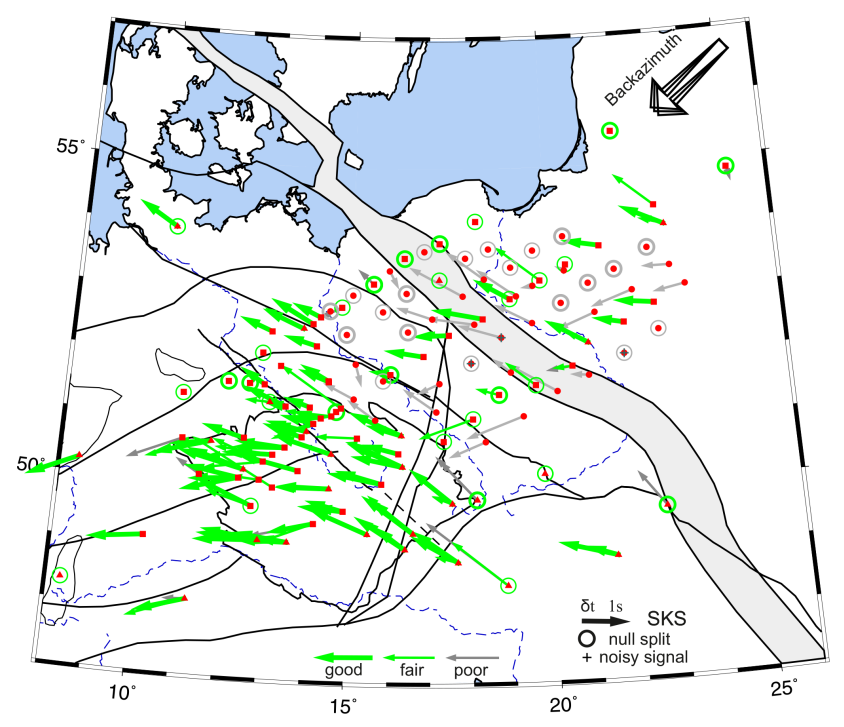

Figure 8. Azimuths $\varphi$ of the fast shear-wave polarizations and the split-delay times $\delta t$ evaluated for three events from the NE back azimuths. Anisotropic signal dominate in the Bohemian Massif, null splits or small provinces with coherent polarizations exist west and north of the Bohemian Massif. Complementary measurements at stations equipped with 2-3 s seismometers are shown in light-grey colour.

shear-wave polarizations at individual stations do not change for waves arriving from the narrow band of the NE back azimuths. 


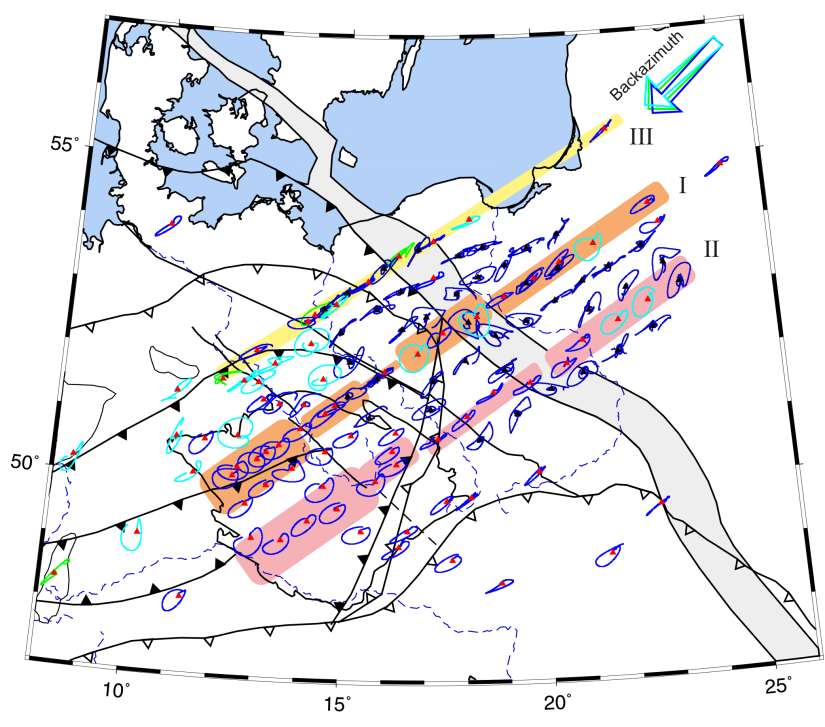

Figure 9. PMs for three events from the NE (the same as in Fig. 8). To emphasize variations of the PM across and along the TESZ, three profiles of the BB stations are marked by coloured bands, whose widths are in relation to the width of the PM ellipses: orange - three areas of broad PMs (in the BM, TESZ/TTZ and EEC) along profile I; red - broad PMs in the BM, followed by narrow PMs, getting gradually broader in the EEC along profile II; yellow - mostly linear PMs along profile III.

Waves propagating from the NW (Figs. 10 and 11) also clearly demonstrate regional variability of the splitting parameters, though for these directions we evaluate a large number of apparent null splits from very narrow PMs in a much larger portion of the PASSEQ array than for waves from the NE. Null splits dominate in the western part of the array beneath the TESZ, between the BM and TESZ and beneath a large part of the BM. On the other hand, strong and coherent fast polarizations are evaluated at most stations of the eastern part of the array, as well as at several stations north of the TTZ in the EEC, the latter with less well coherent polarization orientations.

At some stations (e.g. CLL, Fig. 12), we evaluate splitting parameters which differ significantly even for data from a narrow band of azimuths, even if only relatively stable solutions are considered. We show how sensitive are the results to a width of the elliptical particle motion for a subset of the PASSEQ stations. As expected, the wider the PM, the more stable a splitting solution we get (compare the results for stations PC21, MOX and CLL, Fig. 12). Split delay times at the CLL attain values from near null split (i.e. undefined $\delta t$ ) to $\delta t=1.2 \mathrm{~s}$, with diffused fast polarization azimuths. In general, we attribute the different polarization azimuths to a signal distortion due to noise, or to a local structure including a shallow one. The CLL station is located at the boundary between the consistently split shear waves in the BM and null splits northwest of the BM. The complex structure in the rim

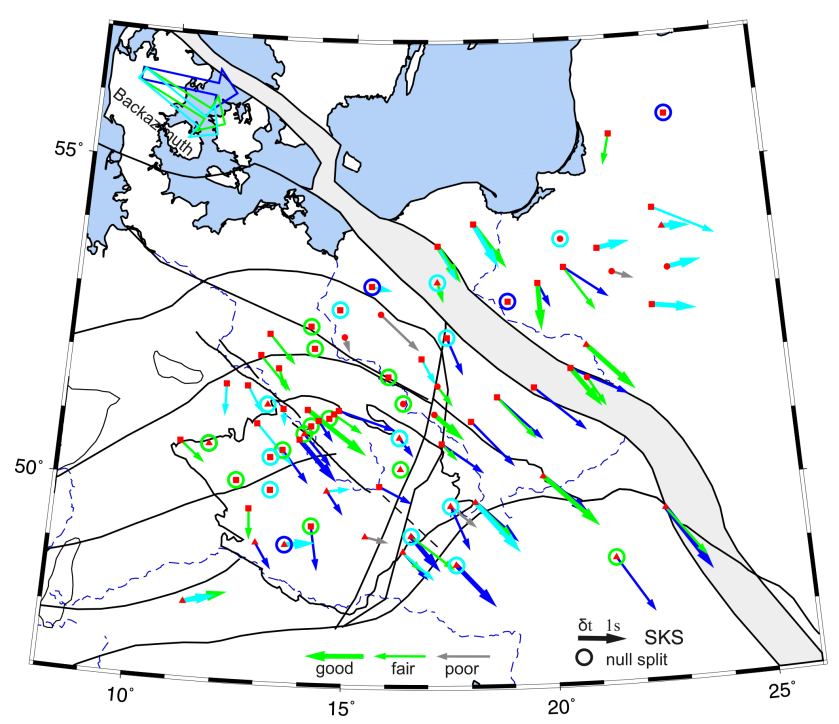

Figure 10. Azimuth $\varphi$ of the fast shear-wave polarizations and delay times $\delta t$ evaluated for four events from the NW back azimuths. Green arrows represent results stacked for two events. Nulls or nearnull splitting prevail in the BM and in the western part of the array, whereas stations east of the Moravian Line show strong anisotropic signal for this back-azimuth interval.

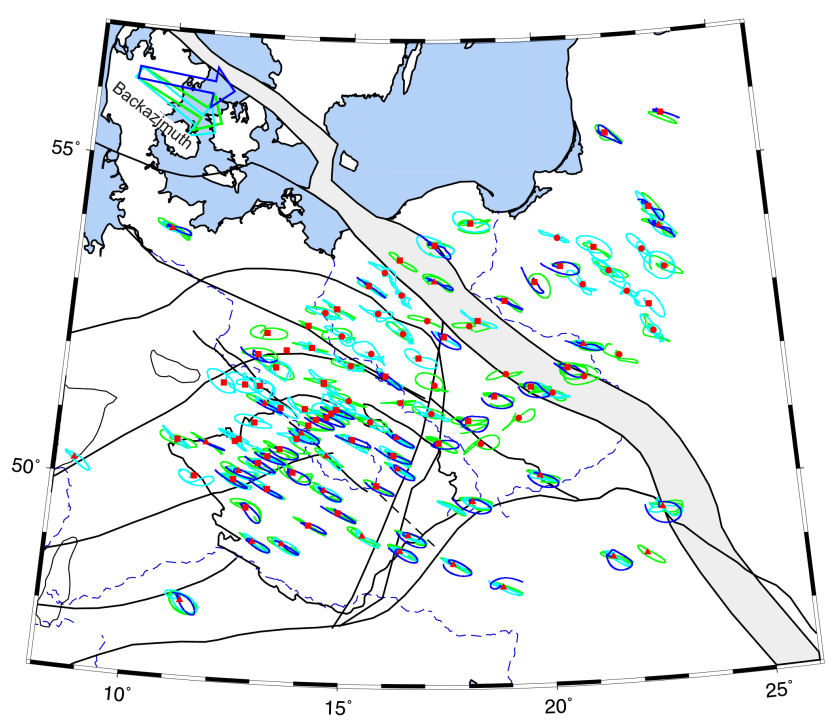

Figure 11. PMs for the same events from the NW as in Fig. 10.

of the BM affects significantly the splitting parameters evaluated even from waves arriving from very close directions.

Not only the amount of energy content on the $T$ component (see Fig. 3), determining the width of PM ellipse, is decisive for reliability of splitting results. For example, if the $Q / T$ amplitude ratio is $\sim 10: 3$ then a signal/noise ratio $\sim 4: 1$ on the $T$ component is a minimum value indicating a good reliability of the results (Table 2), besides the bootstrap measures (Vecsey et al., 2008) in the case of splitting 


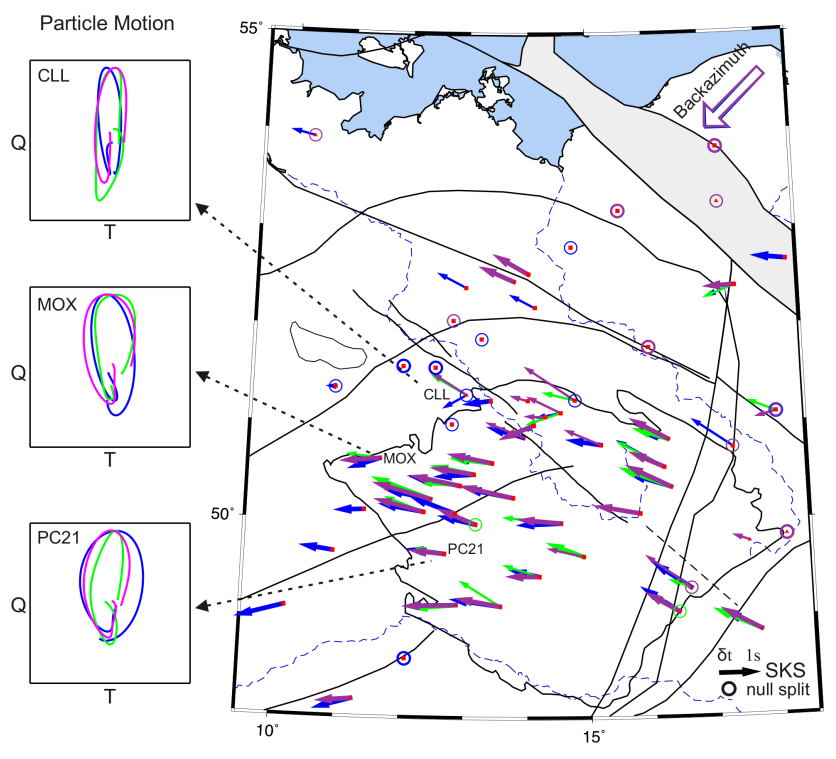

Figure 12. Shear-wave polarizations evaluated at a part of the PASSEQ array from recordings of three events. Splitting parameters evaluated from narrow PM of waves arriving from very close directions differ at station CLL, while we get identical splitting parameters from the broad PM at e.g. station PC21. Complex structures can affect significantly the splitting parameters of waves arriving even from very close directions.

being classified as "good". Interpreting results at stations which have only few data and without proper quality checking could lead to wrong inferences on the upper mantle structure (see also Liu and Gao, 2013).

\section{Discussion}

Similarly to other continental regions (e.g. Plomerová and Babuška, 2010), anisotropic signals that originate in the upper mantle vary in different provinces covered by the PASSEQ array. Respective mantle regions seem to be delimited by distinct tectonic features. Two types of changes of apparent polarization parameters, i.e. fast $S$ polarization and time delay $\delta t$ variations, need to be considered - (1) at individual stations of the array in dependence on direction of wave propagation as well as (2) regional variations for particular directions of propagation. The former leads to 3-D modelling of a structure of individual mantle domains, the second to delimiting approximate domain boundaries. Reliable modelling of anisotropic structures in 3-D requires a good directional coverage, which is impossible in the case of the SKS waves. Nevertheless, a regionalization of the mantle, based on changes of evaluated anisotropic parameters is plausible.

We concentrate on the variable component of the splitting parameters which we associate with the lithosphere structure. The southern part of the PASSEQ array covers the Bo- hemian Massif (BM), where detailed and intensive research of the anisotropic structure of the lithosphere has been carried out. Joint inversion of anisotropic parameters of body waves (shear-wave splitting and $P$ wave travel residuals) resulted in the retrieval of several domains of mantle lithosphere with different anisotropic structure forming the massif (see Babuška and Plomerová, 2013, for review). North of the BM regional changes of anisotropic signal are smooth and less distinct.

The anisotropic signal detected in different regions is used in association with the present-day flow in the asthenosphere. However, European plate moves very slowly without a clear direction (e.g. Gripp and Gordon, 2002). Also recent geodynamic models of mantle flow (Conrad and Behn, 2010) give a very slow flow, if any, in the mantle beneath the whole of Europe. We thus cannot expect a substantial contribution from the asthenosphere to the overall anisotropy pattern. Therefore, similarly to the BM lithosphere, we associate a substantial component of the evaluated anisotropy with mantle lithosphere structure. Though small-scale anisotropic structures are common in the crust, it is generally accepted that only up to $\sim 0.3 \mathrm{~s}$ of the split delay time can be attributed to anisotropy of the heterogeneous crust (e.g. Huang et al., 2011). Moreover, the steeply propagating SKS waves do not split in transversally isotropic media with vertical axis of symmetry (e.g. sedimentary basins).

\subsection{Lateral changes of splitting parameters and tectonics westward of the TTZ}

Complex tectonics of Phanerozoic Europe - westward of the TTZ - is reflected in variations of the PMs and the splitting parameters at stations in this part of the PASSEQ array. The north-south oriented Variscan Front (VF) around the $\sim 16^{\circ}$ E, paralleling the Moravian Line (Fig. 1), separates the narrow PM beneath the Brunovistulian (BV), Upper Silesian (US), Malopolska (MM) and Lysogory (LU) terranes from the strong anisotropic signal within the major part of the Bohemian Massif for waves from the NE (Fig. 9). Similarly, this part of the VF separates weak anisotropic signals in the BM for waves from the NW and the significant anisotropic signal in the Brunovistulian, US, MM and LU (Fig. 10). This means that anisotropic structures west and east of this part of the VF differ and none of them can be approximated by a simple anisotropic model with horizontal symmetry axis.

Split delay times around 1s locate the main source of the anisotropy into the upper mantle and the regional character of the splitting in correlation with the large-scale tectonics indicates that a major part of the anisotropic signal most probably originates in the mantle lithosphere. A simple estimate of a depth interval, where the source of anisotropy might be located if considering Fresnel zones of rays approaching two nearby stations (e.g. Alsina and Snieder, 1995; Chevrot et al., 2004), can be used only in the case of azimuthal anisotropy, i.e. when the mantle fabric can be approximated 
by anisotropic models with horizontal symmetry axis. However, this is not generally valid for complex fabrics of the continental mantle lithosphere (e.g. Babuška and Plomerová, 2006). Particularly, there is the issue of the upper limit of estimated depth interval (minimum depth) to which the source of anisotropy can be located. Considering anisotropy with an inclined symmetry axis and evaluating the splitting parameters in the $Q T$ plane, we get different splitting parameters for waves approaching the station steeply, but from opposite azimuths. The resulting splitting (fast $S$ polarization and $\delta t$ ) depends on direction of propagation, while when considering the azimuthal anisotropy (i.e. as a 2-D phenomenon), the fast $S$ polarization is "constant" and the fast $S$ azimuth is generally used in association with the orientation of the symmetry axes. In the case of dipping symmetry axes, we lose information about the minimum depth below which the source of anisotropy might be located (e.g. depth $z 1$ in Alsina and Snieder, 1995) and we cannot associate the fast $S$ polarization azimuth (either average values or polarizations for a particular back azimuth) directly with the symmetry axis, but have to invert for that.

Previous studies of the upper mantle structure beneath the $\mathrm{BM}$, based on data of a series of passive seismic experiments from 1998 to 2009 and with the use of different seismological techniques, model the BM mantle lithosphere as an assemblage of several domains retaining their own fossil fabrics (Plomerová et al., 2007, 2012a; Karousová et al., 2012, 2013; Geissler et al., 2012; Babuška and Plomerová, 2013). Joint analysis and inversion of anisotropic parameters of body waves resulted in 3-D self-consistent anisotropic models of the domains with differently oriented and inclined symmetry axes. Processing data from dense networks of the BOHEMA II and III passive seismic experiments identified two domains in the Brunovistulian mantle lithosphere. Its southern part underthrust the eastern edge of the BM up to about $100 \mathrm{~km}$ westward beneath the Moldanubian (MD) part of the massif (Babuška and Plomerová, 2013). The northern part of the Brunovistulian mantle lithosphere, covered by the US crustal terrane, steeply collides with the Sudetes in the northeastern BM (Plomerová et al., 2012a). The authors suggested that the southern and northern fragments of the Brunovistulian micro-plate, separated by the Elbe Fault Zone (EFZ, dashed line in Fig. 1) might have originally belonged to different plates, i.e. Gondwana and Baltica, respectively. Seismic data from the PASSEQ array including directional variations of $\mathrm{P}$-wave residuals suggest a continuation of the northern Brunovistulian anisotropic signal without significant changes towards the TTZ (Vecsey et al., 2013), which thus provides additional support for the idea. Moreover, anisotropic signals in P-spheres in the northern half of the PASSEQ stations (Plomerová et al., 2012b) resemble, in general, those found beneath the southernmost tip of the Baltic Shield (Plomerová et al., 2002; Eken et al., 2010).

In this paper, we mainly concentrate on the region north and northeast of the $\mathrm{BM}$, where anisotropic signal changes significantly. Our shear-wave splitting measurements from PASSEQ data indicate prevailingly smooth changes in mantle fabrics northward of the BM. Null splits or weak anisotropic signals prevail at stations along the Rheic Suture and in the easternmost part of the Rhenohercynian domain that parallels the TESZ (Figs. 1 and 8-11). However, within this domain of potential low anisotropy, two relatively small regions with consistent anisotropic signal are detected by waves propagating from the NE. The first one is located between the most bent part of the VF and the Rheic Suture, the second one seems to be linked with crossing of the VF and Moravian Line, in close vicinity to the TTZ. However, apart from the complex tectonics, waveforms at stations in the TESZ suffer from noise due to the thick sedimentary cover of the crystalline basement. Distinct SKS polarizations of waves from the NW in the Brunovistulian domain, as well as delay times between 1 and $2 \mathrm{~s}$, remain almost unchanged across the TESZ towards the EEC (Fig. 10), whereas polarizations of SKS waves arriving from the NE change abruptly at the TTZ (see station line II in Fig. 8).

\subsection{Lateral changes of splitting parameters and tectonics eastward of the TESZ}

Regional variations of the splitting parameters, as well as their back-azimuth dependences, occur also eastward of the TESZ, but groups of stations with similar anisotropic parameters are less coherent than those in Variscan provinces westward of the TTZ. Also, linking these variations with the large-scale tectonics of this Precambrian region is not as straightforward as it is in the Phanerozoic part of Europe, or as is possible in the case of the northern Fennoscandian lithosphere, where Plomerová et al. (2011) relate, e.g. a significant change in mantle fabrics to the Baltic-Bothnia megashear Zone (BBZ). Nevertheless, the splitting parameters at PASSEQ stations in the EEC and the sensitivity of the splitting parameters on back azimuth of arriving waves indicate a domain-like structure also in this part of the EEC. Unfortunately, insufficient amount of shear waveforms, needed for a detailed analysis and modelling of the upper mantle fabrics, were recorded in this part of the PASSEQ array. In general, both the directional and lateral variations in the splitting parameters confirm our previous inferences (e.g. Vecsey et al., 2007; Babuška et al., 2008; Plomerová et al., 2012a) that fabrics of the continental mantle lithosphere have to be modelled in 3-D with generally oriented symmetry axes.

In light of the domain-like structure of the continental lithosphere identified in different tectonic provinces (e.g. Babuška and Plomerová, 2006), it is surprising that we do not observe a distinct change of the apparent splitting parameters across the TESZ/TTZ, one of the most prominent tectonic features in the European continent. Instead, we evaluate mainly smooth changes in SKS polarizations, or even a large number of null splits northward of the BM and further across the TESZ towards the EEC. Such observations indicate less 
coherent fabrics and a transitional change of mantle structure beneath the surface trace of the TESZ/TTZ.

\subsection{Changes of splitting parameters and tectonics in the northwestern (Thor, STZ) and central (TTZ) parts of the TESZ}

The two sutures in the western part of the TESZ - the Thor Suture and Sorgenfrei-Tornquist Zone (STZ, see Fig. 1) sharply delimit domains of the mantle lithosphere of the Baltic Shield, the Danish block (Laurentia), and the North German Platform (Avalonia, see Pharaoh, 1999). The domains, representing fragments of Fennoscandia, Laurentia and Avalonia, differ in fabrics and lithosphere thickness distinctly (Plomerová et al., 2002; Cotte et al., 2002; Shomali et al., 2002; Babuška and Plomerová, 2004). On the other hand, a similar sharp change in lithosphere structure linked with the central part of the TESZ covered by the PASSEQ array, where the TTZ marks the crustal edge of the EEC on the surface, is not evident.

Anisotropic signal can be detected if the SKS propagates through an anisotropic block of a thickness which is comparable with the wavelength (Plomerová et al., 2011). Moreover, from lateral changes of anisotropic parameters of body waves we can assess an inclination and thickness of boundary zones between the anisotropic domains of mantle lithosphere. For example, steep boundaries were retrieved in the MC (Babuška et al., 2002), in the BM (Plomerová et al., 2007), and in northern Fennoscandia (Plomerová et al., 2011), whereas an inclined boundary was modelled in the Proterozoic/Archean contact zone in south-central Finland (Vecsey et al., 2007).

In analogy with the previous results, we can deduce that the narrow near-vertical TTZ in the crust, representing the northeastern boundary of the TESZ (Dadlez et al., 2005), does not have a steep and narrow continuation in the mantle lithosphere. Instead, we suggest a complex transition zone between the Precambrian and Phanerozoic Europe, where various lithospheric fragments, possibly originally belonging to the EEC, underthrust the Phanerozoic domains. Berthelsen (1992) suggested that the TESZ crust was formed by an assemblage of suspect terranes adjoining the EEC edge from the southwest. Our measurements of anisotropy indicate a relatively broad transitional zone in between the two lithospheric segments of different ages. Depth estimates of the lithosphere-asthenosphere boundary (LAB) situate this important "discontinuity" to $\sim 140 \mathrm{~km}$ in the west and down to $\sim 200 \mathrm{~km}$ in the east of the TESZ (Plomerová and Babuška, 2010; Knapmeyer-Endrun et al., 2013). The mantle lithosphere thus seems to be thick enough to accommodate anisotropic signal detected by the shear-wave splitting analysis. However, considering the SKS wavelength of $\sim 40 \mathrm{~km}$, which corresponds to $\sim 8-10$ s dominant periods of teleseismic shear waveforms, the crust thickness of $\sim 40 \mathrm{~km}$ and a wedge-like structure of the contact with a transition be- tween the blocks, we do not observe a consistent pattern of anisotropic signals in the split shear waves and a sharp change of the splitting parameters which would reflect a sharp change of the upper mantle structure.

\subsection{A note on the geodynamic development of the region around the TESZ}

Dadlez et al. (2005) suggested a scenario of the tectonic development of the TESZ involving detachments of elongated and narrow slivers of the Baltica crust, their northwest wandering along anticlockwise rotated Baltica (OrdovicianEarly Silurian; Torsvik et al., 1996) and later their reaccretion to Baltica meeting with docked Avalonia. Nowadays, these pieces are supposed to form the basement of the TESZ crust in northwestern and central Poland. Grad et al. (2008) interpret the high-velocity lower crust extending southwestward of the TESZ as far as beneath the ForeSudetic block, as the edge of Baltica crust. Malinowski et al. (2013) revealed a complex pattern of the Paleozoic and Alpine accretion at the EEC margin. But based on a deep seismic reflection profile, they interpret a westward extent of the EEC lower crust only to the TTZ. Further to the southwest they do not associate the reflective horizon with the top of the EEC crystalline basement, but with a different reflective zone in the uppermost part of the lower BM crust towards the Carpathian Fold-and-Thrust belt. Our results on deep lithosphere structure suggest that fragments of the Precambrian mantle lithosphere most probably underthrust the Proterozoic platform west of the TTZ and might even penetrate the mantle southward as far as to the EFZ in the eastern BM (northern part of the Brunovistulian). The complex structure of the upper mantle, as well as underthrusting of microplate fragments in the TESZ, might contribute to the largest discrepancy in magnetotelluric and seismological LAB depth estimates ever found in the European continent (Jones et al., 2010).

Prevailingly smooth changes of the anisotropic signal (including the nulls) across the TESZ contrast with significant changes in splitting parameters along the TTZ. The notable change occurs around the TTZ intersection with $\sim 18^{\circ} \mathrm{E}$ longitude, close to the edge of the LU and MM units (Pharaoh, 1999; see also Fig. 1), which are along with the Brunovistulian domain associated with Baltica (Dadlez et al., 2005). NW of this "triple junction", a narrow band of the Avalonian fragment is squeezed in between the TTZ and the VF. Narkiewicz et al. (2011) study in detail crustal seismic velocity structure and demonstrate a "preserved memory" of a preDevonian terrane accretion at the East European Platform margin. The authors took into consideration geological and potential field evidence that allowed them to interpret Upper Silesia, Malopolska and Lysogory blocks as separate crustal units, though without precise marking sutures between the particular exotic terranes identified by sharp lateral gradients in the velocity models. This may also lead to discrepancies 
in delimiting units in tectonic schemes of different authors (e.g. Pharaoh et al., 1999; Dadlez et al., 2005) and to leaving distinction between some of the units as an open question (Narkiewicz et al., 2011).

Babuška et al. (1998) deduced from depth variations of surface-wave radial and azimuthal anisotropy that the lateral extent of the mantle lithosphere of Precambrian units is larger than the extent of mapped crustal terranes. Offsets between mantle and crust boundaries of tectonic units, attaining several tens of $\mathrm{km}$ as a result of the lower-crust/mantle decoupling, are often observed (e.g. Babuška et al., 2008). Therefore, based on characteristics of the anisotropy evaluated from shear-wave splitting, we suggest that the EEC mantle lithosphere can penetrate into the Phanerozoic part of European plate southwest of the TTZ, beneath the TESZ and probably even farther beneath the Variscan provinces, regardless of which interpretations of the crustal terranes, concerning particularly the Baltica lower-crust extent, are adopted.

\section{Conclusions}

We have analysed splitting of shear waves (SKS phases) recorded during the PASSEQ passive experiment focused on a study of the upper mantle structure across the TransEuropean Suture Zone (TESZ). 1009 pairs of the delay times of the slow split shear waves and orientations of the polarized fast shear waves exhibit lateral variations within the array, even if evaluated from the same event. Individual measurements at a station depend on back azimuths as well. Particular attention was paid to tests of the northward orientation of seismometers to avoid misinterpretations of the mantle structure due to the instrument misalignment. We identified seismometer misorientations exceeding $10^{\circ}$ not only at several portable stations, but also at some observatories.

While a distinct regionalization of the mantle lithosphere according to anisotropic structure exists in the Phanerozoic part of Europe, a correlation with the large-scale tectonics around the TESZ and in the East European Craton (EEC) is less evident. No general and abrupt change in the splitting parameters can be related to the TTZ, marking the edge of the Precambrian province on the surface. Significant change of the mantle lithosphere structure appears at the northern edge of the Variscan Bohemian Massif (BM). Distinct regional variations of anisotropic structure can also be followed along the TESZ/TTZ, while changes across the zone are gradual. Based on geographical variations of shear-wave splitting, we suggest a southwestward continuation of the Precambrian mantle lithosphere beneath the TESZ, and probably even further southwest.

\section{PASSEQ Working Group}

Monika Wilde-Piorko (University of Warsaw, Warsaw, Poland), Wolfram H. Geissler (Alfred Wegener Insti- tute for Polar and Marine Research, Bremerhaven, Germany), Jaroslava Plomerová (Institute of Geophysics Czech Academy of Sciences, Prague, Czech Republic), Marek Grad (University of Warsaw, Warsaw, Poland), Vladislav Babuška (Institute of Geophysics Czech Academy of Sciences, Prague, Czech Republic), Ewald Bruckl (Vienna University of Technology, Vienna, Austria), Jolanta Cyziene (Geological Survey of Lithuania, Vilnius, Lithuania), Wojciech Czuba (Institute of Geophysics Polish Academy of Sciences, Warsaw, Poland), Richard England (University of Leicester, Leicester, UK), Edward Gaczyński (Institute of Geophysics Polish Academy of Sciences, Warsaw, Poland), Renata Gaždová (Institute of Rock Structure and Mechanics Czech Academy of Sciences, Prague, Czech Republic), Soren Gregersen (Geological Survey of Denmark and Greenland, Copenhagen, Denmark), Aleksander Guterch (Institute of Geophysics Polish Academy of Sciences, Warsaw, Poland), Winfried Hanka (University of Leicester, Leicester, UK), Endre Hegedús (Eötvös Loránd Geophysical Institute, Budapest, Hungary), Barbara Heuer (GeoForschungsZentrum Potsdam, Potsdam, Germany), Petr Jedlička (Institute of Geophysics Czech Academy of Sciences, Prague, Czech Republic), Jurga Lazauskiene (Geological Survey of Lithuania, Vilnius, Lithuania; University of Vilnius, Vilnius, Lithuania), G. Randy Keller (University of Oklahoma, Norman, USA), Rainer Kind (GeoForschungsZentrum Potsdam, Potsdam, Germany), Klaus Klinge (Seismological Central Observatory, Erlangen, Germany), Petr Kolinsky (Institute of Rock Structure and Mechanics Czech Academy of Sciences, Prague, Czech Republic), Kari Komminaho (University of Helsinki, Finland), Elena Kozlovskaya (University of Oulu, Oulu, Finland), Frank Kruger (University of Potsdam, Germany), Tine Larsen (Geological Survey of Denmark and Greenland, Copenhagen, Denmark), Mariusz Majdański (Institute of Geophysics Polish Academy of Sciences, Warsaw, Poland), Jiří Málek (Institute of Rock Structure and Mechanics Czech Academy of Sciences, Prague, Czech Republic), Gediminas Motuza (University of Vilnius, Vilnius, Lithuania), Oldřich Novotný (Institute of Rock Structure and Mechanics Czech Academy of Sciences, Prague, Czech Republic), Robert Pietrasiak (Institute of Geophysics Polish Academy of Sciences, Warsaw, Poland), Thomas Plenefisch (Seismological Central Observatory, Erlangen, Germany), Bohuslav Růžek (Institute of Geophysics Czech Academy of Sciences, Prague, Czech Republic), Saulius Sliaupa (Geological Survey of Lithuania, Vilnius, Lithuania), Piotr Środa (Institute of Geophysics Polish Academy of Sciences, Warsaw, Poland), Marzena Świeczak (Institute of Geophysics Polish Academy of Sciences, Warsaw, Poland), Timo Tiira (University of Helsinki, Finland), Peter Voss (Geological Survey of Denmark and Greenland, Copenhagen, Denmark), PawełWiejacz (Institute of Geophysics Polish Academy of Sciences, Warsaw, Poland). 


\section{The Supplement related to this article is available online at doi:10.5194/se-5-779-2014-supplement.}

Acknowledgements. Contributions of all members of the PASSEQ working group are greatly appreciated. The field works and research of the Czech team was supported by grant no. IAA300120709 of the Grant Agency of the Academy of Sciences and no. 210/12/2381 of the Grant Agency of the Czech Republic. Data acquisition from permanent observatories was supported by the project of large research infrastructure CzechGeo, grant no. LM2010008.

Special Issue: "The Lithosphere-Asthenosphere

Boundary (LAB) Dilemma"

Edited by: U. Achauer, J. Plomerova, and R. Kind

\section{References}

Alsina, D. and Snieder, R.: Small-scale sublithospheric continental mantle deformations: constraints from SKS splitting observations, Geophys. J. Int., 123, 431-448, 1995.

Artemieva, I. M.: The continental lithosphere: reconciling thermal, seismic, and petrologic data, Lithos, 109, 23-46, 2009.

Babuška, V. and Plomerová, J.: Sorgenfrei-Tornquist Zone as the mantle edge of Baltica lithosphere: new evidence from threedimensional seismic anisotropy, Terra Nova, 16, 243-249, 2004.

Babuška, V. and Plomerová, J.: European mantle lithosphere assembled from rigid microplates with inherited seismic anisotropy, Phys. Earth Pl. Int., 158, 264-280, doi:10.1016/j.pepi.2006.01.010, 2006.

Babuška, V. and Plomerová, J.: Boundaries of mantle-lithosphere domains in the Bohemian Massif as extinct exhumation channels for high-pressure rocks, Gondwana Res., 23, 973-987, doi:10.1016/j.gr.2012.07.005, 2013.

Babuška, V., Montagner, J.-P., Plomerová, J., and Girardin, N.: Agedependent large-scale fabric of the mantle lithosphere as derived from surface-wave velocity anisotropy, Pure Appl. Geophys., 151, 257-280, 1998.

Babuška, V., Plomerová, J., Vecsey, L., Granet, M., and Achauer, U.: Seismic anisotropy of the French Massif Central and predisposition of Cenozoic rifting and volcanism by Variscan suture hidden in the mantle lithosphere, Tectonics, 21, 11-20, doi:10.1029/2001TC901035, 2002.

Babuška, V., Plomerová, J., and Vecsey, L.: Mantle fabric of western Bohemian Massif (central Europe) constrained by 3D seismic $\mathrm{P}$ and S anisotropy, Tectonophysics, 462, 149-163, doi:10.1016/j.tecto.2008.01.020, 2008.

Berthelsen, A.: From Precambrian to Variscan Europe, in: A Continent Revealed - The European Geotraverse, edited by: Blundell, D. J., Freeman, R., and Mueller, St., Cambridge Univ. Press, 153-164, 1992.

Chevrot, S., Favier, N., and Komatitsch, D.: Shear wave splitting in three-dimensional anisotropic media, Geophys. J. Int., 159, 711720, doi:10.1111/j.1365-246X.2004.02432.x, 2004.

Conrad, C. P. and Behn, M. D.: Constraints on lithosphere net rotation and asthenospheric viscosity from global mantle flow models and seismic anisotropy, Geochem. Geophy. Geosy., 11, Q05W05, doi:10.1029/2009GC002970, 2010.

Cotte, N., Pedersen, H. A., and TOR Working Group: Sharp contrast in lithospheric structure across the Sorgenfrei-Tornquist Zone as inferred by Rayleigh wave analysis of TOR1 project data, Tectonophysics, 360, 75-88, doi:10.1016/S00401951(02)00348-7, 2002.

Dadlez, R., Grad, M., and Guterch, A.: Crustal structure below the Polish Basin: Is it composed of proximal terranes derived from Baltica?, Tectonophysics, 411, 111-128, 2005.

Debayle, E. and Richard, Y.: A global shear velocity model of the upper mantle from fundamental and higher Rayleigh mode measurements, J. Geophys. Res., 117, B10308, doi:10.1029/2012JB009288, 2012.

Eken, T., Plomerová, J., Roberts, R., Vecsey, L., Babuška, V., Shomali, H., and Bodvarsson, R.: Seismic anisotropy of the mantle lithosphere beneath the Swedish National Seismological Network (SNSN), Tectonophysics, 480, 241-258, doi:10.1016/j.tecto.2009.10.012, 2010.

Geissler, W. H., Skácelová, Z., Kämpf, H., Plomerová, J., Babuška, V., and Kind, R.: Lithosphere structure of the NE Bohemian Massif (Sudetes) - A teleseismic receiver function study, Tectonophysics, 564-565, 12-37, doi:10.1016/j.tecto.2012.05.005, 2012.

Gregersen, S., Voss, P., and TOR Working Group: Project TOR: on the sharpness of the deep lithosphere transition across GermanyDenmark-Sweden, Tectonophysics, 360, 61-73, 2002.

Grad, M., Janik, T., Yliniemi, J., Guterch, A., Luosto, U., Tiira, T., Komminaho, K., Środa, P., Höing, K., Makris, J., and Lund, C.-E.: Crustal structure of the Mid-Polish Trough beneath the Teisseyre-Tornquist Zone seismic profile, Tectonophysics, 314, 145-160, 1999.

Grad, M., Jensen, S. L., Keller, G. R., Guterch, A., Thybo, H., Janik, T., Tiira, T., Yliniemi, J., Luosto, U., Motuza, G., Nassedkin, V., Czuba, W., Garcyński, E., Środa, P., Miller, K. C., Wilde-Piorko, M., Komminaho, K., Jacyna, J., and Korabliova, L.: Crustal structure of the Trans-European Suture Zone region along POLONAISE'97 seismic profile P4, J. Geophys. Res., 108, 2541, doi:10.1029/2003JB002426, 2003.

Grad, M., Guterch, A., Mazur, S., Keller, G. R., Špičák, A., Hrubcová, P., and Geissler, W. H.: Lithospheric structure of the Bohemian Massif and adjacent Variscan belt in central Europe based on profile S01 from the SUDETES 2003 experiment, J. Geophys. Res., 113, B10304, doi:10.1029/2007JB005497, 2008.

Gripp, A. E. and Gordon, R. G.: Young tracks of hotspots and current plate velocities, Geophys. J. Int., 150, 321-361, doi:10.1046/j.1365-246X.2002.01627.x, 2002.

Guterch, A., Grad, M., Materzok, R., and Perchuć, E.: Deep structure of the Earth's crust in the contact zone of the Palaeozoic and Precambrian Platforms in Poland (Tornquist-Teisseyre zone), Tectonophysics, 128, 251-279, 1986.

Guterch, A., Grad, M., Jasnik, T., Materzok, R., Luosto, U., Ylieniemi, J., Lück, E., Schulze, A., and Förste, K.: Crustal structure of the transition zone Precambrian and Variscan Europe fom new seismic data slony LT-7 profile (NW Poland and eastern Germany), C. R. Acad. Sci. Paris, 319 (Ser. II), 1489-1496, 1994.

Hjelt, S.-E., Korja, T., Kozlovskaya, E., Yliniemi, J., Lahti, I., and BEAR and SVEKALAPKO Working Groups: Electrical conductivity and seismic velocity structures of the lithosphere beneath 
the Fennoscandian Shield, in: European Lithosphere Dynamics, edited by: Gee, D. G. and Stephenson, R. A., Geol. Soc. Memoirs, 32, 541-559, doi:10.1144/GSL.MEM.2006.032.01.33, 2006.

Huang, Z., Zhao, D., and Wang, L.: Shear wave anisotropy in the crust, mantle wedge, and subducting Pacific slab under northeast Japan, Geochem. Geophy. Geosys., 12, Q01002, doi:10.1029/2010GC003343, 2011.

Janik, T., Yliniemi, J., Grad, M., Thybo, H., Tiira, T., and POLONAISE P2 Working Group: Crustal structure across the TESZ along POLONAISE'97 seismic profile P2 in NW Poland, Tectonophysics, 360, 129-152, 2002.

Janik, T., Grad, M., Guterch, A., Dadlez, R., Yliniemi, J., Tiira, T., Keller, G. R., Gaczyński, E., and CELEBRATION 2000 Working Group: Lithospheric structure of the Trans-European Suture Zone along the TTZ-CEL03 seismic transect (from NW to SE Poland), Tectonophysics, 411, 129-156, 2005.

Jones, A. G., Plomerová, J., Korja, T., Sodoudi, F., and Spakman, W.: Europe from the bottom up: A statistical examination of the central and northern European lithosphere-asthenosphere boundary from comparing seismological and electromagnetic observations, Lithos, 120, 14-29, 2010.

Karousová, H., Plomerová, J., and Vecsey, L.: Seismic tomography of the upper mantle velocity structure beneath the north-eastern Bohemian Massif (central Europe), Tectonophysics, 564-565, 111, doi:10.1016/j.tecto.2012.06.031, 2012.

Karousová, H., Plomerová, J., and Babuška, V.: Upper-mantle structure beneath the southern Bohemian Massif and its surroundings imaged by high-resolution tomography, Geophys. J. Inter., 194, 1203-1215, doi:10.1093/gji/ggt159, 2013.

Knapmeyer-Endrun, B., Krüger, F., Legendre, C. P., Geissler, W. H., and PASSEQ Working Group: Tracing the influence of the TransEuropean Suture Zone into the mantle transition zone, Earth Planet. Sc. Lett., 363, 73-87, 2013.

Liu, K. H. and Gao, S. S.: Making reliable shear-wave splitting measurements, Bull. Seismol. Soc. Am., 103, 2680-2693, doi:10.1785/0120120355, 2013.

Majorowicz, J. A., Čermák, V., Šalanda, J., Krzywiec, P., Wróblewska, M., Guterch, A., and Grad, M.: Heat flow models across the Trans-European Suture Zone in the area of the POLONAISE'97 seismic experiment, Phys. Chem. Earth, 28, 375-391, 2003.

Malinowski, M., Guterch, A., Narkiewicz, M., Probulski, J., Maksym, A., Majdański, M., Środa, P., Czuba, W., Gaczyński, E., Grad, M., Janik, T., Jankowski, M., and Adamczyk, A.: Deep seismic reflection profile in Central Europe reveals complex pattern of Paleozoic and Alpine accretion at the East European Craton margin, Geophys. Res. Lett., 40, 3841-3846, doi:10.1002/grl.50746, 2013.

Menke, W. and Levin, V.: The cross-convolution method for interpreting SKS splitting observations, with application to one and two-layer anisotropic earth models, Geophys. J. Int., 154, 379392, 2003

Narkiewicz, M., Grad., M., Guterch, A., and Janik, T.: Crustal seismic velocity structure of southern Poland: preserved memory of a pre-Devonian terrane accretion at the East European platform margin, Geol. Mag., 148, 191-210, doi:10.1017/S001675681000049X, 2011.
Pharaoh, T. C.: Palaeozoic terranes and their lithospheric boundaries within the Trans-European Suture Zone (TESZ): a review, Tectonophysics, 314, 17-41, 1999.

Piromallo, C. and Morelli, A.: P wave tomography of the mantle under the Alpine-Mediterranean area, J. Geophys. Res., 108, 2065, doi:10.1029/2002JB001757, 2003.

Plomerová, J. and Babuška, V.: Long memory of mantle lithosphere fabric - European LAB constrained from seismic anisotropy, Lithos, 120, 131-143, doi:10.1016/j.lithos.2010.01.008, 2010.

Plomerová, J., Babuška, V., Vecsey, L., Kouba, D., and TOR Working Group: Seismic anisotropy of the lithosphere around the Trans-European Suture Zone (TESZ) based on teleseismic bodywave data of the TOR experiment, Tectonophysics, 360, 89-114, 2002.

Plomerová, J., Achauer, U., Babuška, V., Vecsey, L., and BOHEMA working group: Upper mantle beneath the Eger Rift (Central Europe): plume or asthenosphere upwelling?, Geophys. J. Int., 169, 675-682, doi:10.1111/j.1365-246X.2007.03361.x, 2007.

Plomerová J., Vecsey, L., Babuška, V., and LAPNET working group: Domains of Archean mantle lithosphere deciphered by seismic anisotropy - inferences from the LAPNET array in northern Fennoscandia, Solid Earth, 2, 303-313, doi:10.5194/se2-303-2011, 2011.

Plomerová, J., Vecsey, L., and Babuška, V.: Mapping seismic anisotropy of the lithospheric mantle beneath the northern and eastern Bohemian Massif (central Europe), Tectonophysics, 564-565, 38-53, doi:10.1016/j.tecto.2011.08.011, 2012a.

Plomerová, J., Babuška, V., Vecsey, L., and PASSEQ working group: Lithosphere - asthenosphere boundary (LAB) around the Trans-European Suture Zone (TESZ), Geophys. Res. Abstr., 14, EGU2012-8782, 2012b.

Shomali, Z. H., Roberts, R. G., and Tor Working Group: Nonlinear body wave teleseismic tomography along the TOR array, Geophys. J. Int., 148, 562-574, doi:10.1046/j.1365246x.2002.01592.x, 2002.

Š́lený, J. and Plomerová, J.: Inversion of shear-wave splitting parameters to retrieve three-dimensional orientation of anisotropy in continental lithosphere, Phys. Earth. Plant. Int., 95, 277-292, 1996.

Silver, P. G. and Chan, W. W.: Shear wave splitting and subcontinental mantle deformation, J. Geophys. Res., 96, 16429-16454, 1991.

Silver, P. G. and Savage, M. K.: The interpretation of shear-wave splitting parameters in the presence of two anisotropic layers, Geophys. J. Int., 119, 949-963, 1994.

Spakman, W.: Delay-time tomography of the upper mantle below Europe, the Mediterranean, and Asia Minor, Geophys. J. International, 107, 309-332, doi:10.1111/j.1365-246X.1991.tb00828.x, 1991.

Środa, P., Czuba, W., Grad, M., Garcyński, E., and Guterch, A.: Three-dimensional seismic modeling of crustal structure in the TESZ region based on POLONAISE'97 data, Tectonophysics, 360, 169-185, 2002.

Torsvik, T. H., Smethurst, M. A., Mečet, J. G., Van Der Voo, R., McKerrow, W. S., Brasier, M. E., Sturt, B. A., and Wylderhaug, H. J.: Continental break-up and collision in the Neoproterozoic and Palaeozoic - a tale of Baltica and Laurentia, Earth Sci. Rev., 40, 229-258, 1996. 
Vecsey, L., Plomerová, J., Kozlovskaya, E., and Babuška, V.: Shearwave splitting as a diagnostic of varying upper mantle structure beneath south-eastern Fennoscandia, Tectonophysics, 438, 5777, doi:10.1016/j.tecto.2007.02.017, 2007.

Vecsey, L., Plomerová, J., and Babuška, V.: Shear-wave splitting measurements - problems and solutions, Tectonophysics, 462, 178-196, doi:10.1016/j.tecto.2008.01.021, 2008.

Vecsey, L., Plomerová, J., Eken, T., and Babuška, V.: Role of seismic anisotropy in isotropic tomographic models of the upper mantle, Geophys. Res. Abstr., 13, EGU2011-3164, 2011.

Vecsey, L., Plomerová, J., Babuška, V., and PASSEQ Working Group: Structure of the mantle lithosphere around the TESZ from the East European Craton to the Variscan Belt, EGU General Assembly 2013, Geophys. Res. Abstr., 15, EGU2013-3133, 2013.

Vinnik, L. P., Farra, V., and Romanowicz, B.: Azimuthal anisotropy in the Earth from observations of SKS at GEOSCOPE and NARS broadband stations, Bull. Seismol. Soc. Am., 79, 1542-1558, 1989.
Wilde-Piórko, M., Grad, M., and POLONAISE Working Group: Regional and teleseismic events recorded across the TESZ during POLONAISE'97, Tectonophysics, 314, 161-174, 1999.

Wilde-Piórko, M., Geissler, W. H., Plomerová, J., and PASSEQ Working Group: PASSEQ 2006-2008: passive seismic experiment in Trans-European Suture Zone, Stud. Geophys. Geod., 52, 439-448, 2008.

Wilde-Piórko, M., Świeczak, M., Grad, M., and Majdański, M.: Integrated seismic model of the crust and upper mantle of the Trans-European Suture Zone between the Precambrian and Phanerozoic terranes in central Europe, Tectonophysics, 481, 108-115, 2010.

Wüstefeld, A. and Bokelmann, G.: Null detection in shear-wave splitting measurements, Bull. Seismol. Soc. Am., 97, 12041211, doi:10.1785/0120060190, 2007. 